all the distributing electric light stations, it has not yet been found practicable to make a lamp which will stand the strain. Hence we have to be content with somewhat indifferent carbon filament lamps.

Before the war many operation lamps such as Jessop's were fitted with a Nernst filament; as this is no longer obtainable the lamp is rendered useless. A very excellent substitute for the Nernst is the Ediswan Pointolight which has been fitted in some instances into the existing tubes by Messrs. Hamblin. This lamp has the disadvantage that it requires a resistance in the circuit, and although suitable for an operating theatre, cannot be carried into wards. Further, it is difficult to bring the filament sufficiently close to the focussing system of lenses to get an even illumination. To obviate this difficulty there has been produced quite recently a spiral metal filament gas-filled lamp, the filament of which is brought close against the glass on one side for projection. It is manufactured in all voltages, and does not require any resistance in the circuit, and can be used in either an operating lamp or in the lamp described below for use in the wards. It is manufactured by the British General Electric Co., and by Siemen Bros. A very excellent ward lamp designed and produced by Messrs. Rayner and Co., in consultation with ophthalmic surgeons and members of the Illuminating Engineering Society. It is readily portable, gives a definite spot of light of even brilliancy, and has discs of ground and Chance's daylight glass to place before it, if desired. The same firm has produced an excellent shadowless lamp for the general lighting of the operating field, which consists of three separate lens systems similar to the hand-lamp, deriving its source of light from a half-watt bulb.

\title{
REPORT OF THE DEPARTMENTAL COMMITTEE ON THE CAUSES AND PREVENTION OF BLINDNESS : CONCLUSION AND SUMMARY OF RECOMMENDATIONS
}

"We have reviewed the principal causes of blindness and defective vision and the methods by which they are at present dealt with. It is certain that much blindness is preventable, but it is not possible to state in exact terms to what extent this is so nor is the remedy always simple. The perfecting of medical diagnosis and technique will effect much, as will the success attending Public Health activity directed against unhygienic environment and conditions inimical to health. Such factors as are associated with conditions of social life, unhealthy habits, malnutrition, etc., cannot be rectified immediately but only by the slow and gradual process of education and the 
attainment of a higher standard of life among the people. Some factors, such as the inheritance of certain eye defects cannot at present be explained, but we are convinced that much can be done to diminish materially the present incidence of blindness.

"Certain factors, predominant in the production of blindness in former days, as smallpox and trachoma, both dependent upon infection, have now been checked, and we have little doubt that a later generation will similarly view some present causes. Ophthalmia neonatorum and syphilis, predominant to-day, are also dependent upon infection, and although the problem of dealing with them is more complicated, success in the campaign against venereal disea se is, in our view, the key to the prevention of blindness from these two causes.

"Blindness due to the diseases of childhood will be diminished by the increased attention which is being given to the welfare of infants, the medical supervision of the school child, the provision of special schools and the guidance in the choice of industry of children with defective vision.

"Blindness arising from industrial conditions is a problem which must be attacked by the continued development of industrial hygiene and the adoption of direct safeguards to diminish further the hazards of industry. The ever changing character of industry will introduce new risks and necessitate constant vigilance against possible causes of blindness or impairment of vision.

"Prevention of blindness from the more strictly medical aspect consists in the efficient treatment of already present disease or injury. Here the first line of defence must be the general practitioner: hence the necessity of an adequate training in Ophthalmology which in our opinion is not at present assured. Further, in view of the frequent occurrence, in disease and injury of the eye, of cases which require the supervision of an ophthalmic surgeon, there must be facilities to ensure that specialist services are readily available. These conditions being fulfilled there would then be less opportunity for the unqualified practitioner whose specious claims too often delude sufferers until the possibility of amelioration has passed.

"We desire to place on record our appreciation of the efficiency and helpfulness of the Secretaries to the Committee. In the earlier stages of our proceedings we had the assistance of Dr. R. A. Farrar, who left to undertake a medical mission in Russia and in that country lost his life during the performance of duties finely and humanely inspired. He was succeeded by Dr. J. Pearse, who has brought to bear on the work of the Committee medical knowledge and personal qualities of a high standard. Mr. P. N. R. Butcher has been with us throughout, and has earned a full share of the tribute we pay to the manner in which the secretarial portion of our labours has been carried out." 


\section{Summary of Recommendations}

"We recommend:-

\section{Ophthalmia Neonatorum-}

(i) that the Ministry of Health should take steps to ensure that adequate nursing provision is always available for cases of Ophthalmia Neonatorum which are not admitted to Hospital ( $\$ 66)$;

(ii) that in every area, whether urban or rural, the Ministry of Health should take measures to secure the provision of suitable hospital accommodation for babies suffering from Ophthalmia Neonatorum and for their mothers $(\S 74)$;

(iii) that arrangements should be made for pupil midwives to visit Ophthalmic Hospitals or the Ophthalmic Departments of General Hospitals for the purpose of gaining direct experience of Ophthalmia Neonatorum ( $\$ 59)$;

(iv) that in cases of suspected Ophthalmia Neonatorum facilities for consultation with an ophthalmic surgeon and for bacteriological investigation should be provided wherever practicable ( $\$ 62)$;

\section{Educational Provision-}

(v) that any infant whose vision is impaired whether from Ophthalmia Neonatorum or any other cause should be brought under the notice of the Local Education Authority at the earliest possible age, and before the normal school age, in order that special education and training may be commenced early (\$.47);

(vi) that adequate provision should be made for the education and treatment in special residential schools of children suffering from phlyctenular keratitis and other forms of chronic external eye disease $(\$ 92)$;

(vii) that the Poard of Education should consider the question of seeking additional powers to enable a Local Education Authority to require a parent to submit a child suspected of suffering from chronic external eye disease to medical inspection and adequate medical treatment where the authority deems such inspection and treatment necessary $(\$ 98)$;

(viii) that further provision should be made by Education Authorities for the education in Myope Classes, or by similar methods, of children with serious defects of vision requiring such facilities, and that steps should be taken to discover these cases at such an early age as will allow of preventive measures being adopted $(\S 124)$;

Medical Education-

(ix) that the General Medical Council again be urged to insist that every student presenting himself for a qualifying examination shall be examined in ophthalmology $(\$ 68)$;

(x) that in sanctioning appointments as Medical Inspectors under the Aliens Acts, the Ministry of Health 
should endeavour as far as possible to secure that such Officers, if they have not already had special experience of contagious eye diseases and particularly of Trachoma, should be afforded the opportunity of acquiring it ( $\$ 114)$;

Industrial Eye Injury-

(xi) that, as soon as the proposals for pooling information in possession of the Insurance Companies regarding accidents have matured, the information should be made available to the Government Departments concerned ( $\$ 139)$;

(xii) that the Home Office should invite the Textile industries to investigate the danger of injury from Flying Shuttles with a view to securing improvement in the guards $(\$ 184)$;

(xiii) that the Home Office should take steps to extend the use of screens on lathes and abrasive wheels and also of sidescreens wherever advantageous use can be made of them in order to give protection against flying particles $(\$ 202)$;

(xiv) that the Home Office should take immediate steps to issue detailed specifications of the most suitable forms of goggles and masks for the respective industrial processes $(\$ 216)$;

(xv) that all possible steps should be taken to encourage the development of Works and Safety Committees with regard to the prevention of accidents, the use of safety devices and methods of propaganda $(\$ 220)$;

(xvi) that the Mines Department should endeavour to extend the use of goggles in quarries and for that purpose enlist the aid of the workmen's and other organisations ( $\$ 243)$;

(xvii) that the Mines Department should require all ambulance stations, above and below ground, to be provided with equipment for the first aid treatment of eye injuries and should take steps to ensure that all cases of eye injury receive adequate first aid treatment at the earliest possible moment $(\$ 248)$."

(Signed)

GEO. H. ROBERTS (Chairman),

C. J. BOND, ·

JOHN C. BRIDGE,

ALFRED EICHHOLZ,

N. BISHOP HARMAN,

J. B. LAWFORD.

E. D. MACGREGOR,

G. F. MOWATt,

J. S. Nicholson,

J. Herbert Parsons,

Jessie P. B. PhIPPS,

W. M. StONE,

JAMES TAYLOR,

STEPHEN WALSH.

$\left.\begin{array}{l}\text { JAMES PEARS E } \\ \text { P. N. R. BUTCHER }\end{array}\right\}$ Secretaries.

September, 1922. 